More Information

\title{
Adverse childhood experiences and their Alcohol, and chat Consumption among school-going adolescents, Ethiopia: Cross-sectional study
}

\section{Mekonnen Tsehay ${ }^{1 *}$, Mogesie Necho ${ }^{1}$, Asmare Belete ${ }^{1}$ and Werkua Mekonnen² \\ 1Department of Psychiatry, College of Medicine and Health Science, Wollo University, Dessie, Ethiopia ${ }^{2}$ Department of Psychiatry, College of Medicine and Health Science, Mekele University, Ethiopia}

\section{Abstract}

Background: Alcohol and chat use during adolescence is associated with academic and health problems, including abuse or dependence in adulthood. The aim of the present study was to investigate associations between adverse childhood experiences (ACEs) and early initiation of alcohol and chat use among school-going adolescents.

Methods: A cross-sectional study was performed with 546 school-going adolescents. The ACE International Questionnaire (ACE-IQ) was used to assess ACEs, Alcohol and chat use was assessed by questions prepared by the authors. Multiple logistic regression models were used to examine the associations between overall ACE score and alcohol use and the potential moderating effects of confounders.

Results: prevalence of chat chewing behavior was $26.6 \%$ followed by alcohol use $20 \%$. A total of $66.2 \%$ of participants reported at least one ACE, and $5.93 \%$ reported four or more ACEs. High/Multiple ACEs (ACEs=1-3 and above 3) were significantly associated with increased alcohol use behaviors $(A O R=1.491(1.072-3.078)$ and $(A O R=3.171(1.330-7.560)$ respectively and increased chat use behaviors by 4.92 times $(A O R=4.92,95 \% \mathrm{Cl}=2.640-8.432)$ and 11.022 times $(\mathrm{AOR}=11.022,95 \% \mathrm{Cl}=1.230-25.560)$ respectively controlling other factors.

Conclusion: ACEs were significantly associated with risk behaviors, alcohol and chat use may lead to poor health, and educational outcomes among adolescent students and numbers of ACEs have graded association. Social support, sex, residence, parent educational status, and current level of depressive symptoms were significant modulating factors, which parents, school teachers, psychologists, and adolescent health care providers should give the concern to decrease the effect on school-going adolescents.

\author{
*Address for Correspondence: \\ Mekonnen Tsehay, Department of Psychiatry, \\ College of Medicine and Health Science, Wollo \\ University, Dessie, Ethiopia, \\ Email: jimma1760@gmail.com
}

Submitted: 13 October 2020

Approved: 04 November 2020 Published: 05 November 2020

How to cite this article: Tsehay M, Necho M, Belete A, Mekonnen W. Adverse childhood experiences and their Alcohol, and chat Consumption among school-going adolescents, Ethiopia: Cross-sectional study. Arch Psychiatr Ment Health. 2020; 4: 076-083.

DOI: $10.29328 /$ journal.apmh.1001025

Copyright: $\odot 2020$ Tsehay M, et al. This is an open access article distributed under the Creative Commons Attribution License, which permits unrestricted use, distribution, and reproduction in any medium, provided the original work is properly cited.

Keywords: Alcohol; Chat; Adverse childhood experience; Social support; Adolescent

Abbreviations: ACES: Adverse Childhood Experiences; ACE-IQ: Adverse Childhood Experiences International Questionnaire; AOR: Adjusted Odds Ratio; AUD: Alcohol Use Disorder; AUDIT: Alcohol Use Disorder Identification Test; Cl: Confidence Interval; OR: Odds Ratio; SUD: Substance Use Disorder; WHO: World Health Organization

\section{A) Check for updates OPEN ACCESS}

\section{Background}

Alcohol has a complex role in the health and economy of Ethiopia society. While many of Ethiopian adults drink alcohol at levels that increase their risk of alcohol-related harm [1]. In many countries, including Ethiopia, alcohol is responsible for a considerable burden of death, disease, and injury; and alcoholrelated harm also affects families, specifically children [2].

Research shows that the burden attributable to substance use increases substantially in a period of adolescence and young adulthood [3]. Alcohol has short-term and long term consequences for adolescents such as injury, violence, self- harm, and risky sexual behavior, and alcohol use during early adolescence is a major risk factor for later alcohol abuse and dependence $[4,5]$.

The use of chat (Catha edulis), alcohol, and other substances is a worldwide problem that especially affects young people [6]. The World Health Organization (WHO) report shows that there are about 2 billion people worldwide who consume alcoholic beverages, of whom 76.3 million are affected by alcohol-related disorders [7].

Excessive drinking has long-lasting effects on adolescent's brain development $[8,9]$. Therefore, this research that 
improves our understanding of the risk factors for adolescent drinking was needed to inform policymakers and other concerned bodies, aimed at improving the health and social outcomes for young Ethiopians.

The overall prevalence of substance use among adolescents in sub-Saharan Africa was $41.6 \%$, with the highest rate in Central Africa at 55.5\% [10]. This meta-analysis study also reported that the use of caffeine-containing products (including coffee or kola nut) was most predominant at $41.2 \%$, followed by alcohol at $32.8 \%$, to bacco products $23.5 \%$, chat $22.0 \%$ and cannabis $15.9 \%$. Other abused substances included depressants at $11.3 \%$, amphetamines $9.4 \%$, heroin $4.0 \%$, and cocaine $3.9 \%$.

Adverse childhood experiences (ACEs) are traumatic events occurring before age 18. Adverse childhood experiences (sometimes referred to as ACEs) are potentially traumatic events that can have negative, long-lasting effects on health, and well-being. These traumatic events range from physical, emotional, or sexual abuse to parental divorce and incarceration of a parent or guardian [11].

The prevalence of any adverse childhood event ranged from $7.9 \%$ to $32 \%$ among women and $20 \%$ to $24 \%$ among men $[12,13]$ and overall prevalence was estimated as $36.3 \%$ in worldwide [14].

World Health Organization with multicultural study in women reported, In Ethiopia, Prevalence of partner violence Nearly one half (49\%) of ever-partnered women experienced physical violence by a partner at some point in their lives, and $29 \%$ during the past 12 months. 59\% of ever-partnered women experienced sexual violence at some point, and $44 \%$ during the past 12 months. Combining the data for physical and sexual violence, $71 \%$ of ever-partnered women experienced one or the other form of violence, or both, over their lifetime. $35 \%$ of all ever-partnered women experienced at least one severe form of physical violence [15].

Childhood development has effects on health and wellbeing throughout life [16]. ACEs lead to poor health outcomes and health-threatening behaviors. High ACE scores in the first eighteen years of life are linked to poor outcomes in physical, and mental health and social functioning.

The ACE study described adverse experiences as "common, stressful, and traumatic exposures affecting the (neuro) development of children" [17]. The hypothesis posits that stressful childhood experiences such as abuse, and neglect, or growing up in a dysfunctional household, create common vulnerability to social, emotional, and cognitive impairments that lead to increased risk of poor health behavior, social adjustment and physical and mental illness.

One mechanism by which adverse childhood experiences result in long-term health consequences is by engaging in adult health-risk-taking behaviors [18]. These include alcohol and drug abuse, having multiple sex partners, cigarette smoking, and compulsive eating leading to Obesity [19-22]. Individuals attempt such behaviors as coping and selfregulating the experiences of emotional pain, anxiety, anger and/or depression related to unresolved adverse childhood experiences [23].

Identifying factors that alter the processing of stressful events following exposure to ACEs may be a valuable tool in developing interventions aimed at preventing or mitigating the long-term health consequences of ACEs [24].

Social support may have a protective or buffering effect against the consequences of a stressful event by enhancing cognitive and emotional processing of the experience and protect people from going to substance uses behaviors [25].

Although ACEs are more prevalent in low- and middleincome countries, like Ethiopia with limited resources and poor health care [26], little is known about their health and risky behaviors impacts. For example, there is limited information on the differential effects of cumulative and individual ACE components and their association with alcohol and chat use in Ethiopia.

The primary objective of the current study was to examine the relationships between individual ACE types (abuse, neglect, and household dysfunction), and high-risk health behaviors in adolescents, early initiation of alcohol, and chat use in Ethiopia. In addition, we examined factors that modify the association between three ACE types (abuse, neglect, and household dysfunction) and early initiation of alcohol and chat use in early and late adolescent periods of adolescents in Ethiopia.

\section{Methods and materials}

\section{Study design and study setting}

The school-based cross-sectional study design was employed. This study was conducted in Jimma town secondary school students. The town has 9383 students in six public (7292), and eight private (2091) high school's registered for grades $9,10,11$, and 12 in the academic year of 2017/18.

\section{Study population}

All adolescent students aged 10-19 who were studying in selected Jimma town secondary schools, and students who are willing and allowed by the parents to participate in the study were recruited. Adolescents found to have severe illness during the study and difficulties in communication to the data collectors were excluded.

\section{Sampling procedures}

The sample size was calculated by taking the prevalence of alcohol use among high school students of eastern Ethiopia which were $22.2 \%$, for the sake of to get large sample size [27]. 
Assuming any particular outcome to be within a $5 \%$ margin of error, and a 95\% confidence interval of, design effect $=2$, and a $10 \%$ nonresponse rate and using a single population proportion formula and the final sample size was 583.

Using a multistage sampling technique two schools from the governmental schools, and three schools from the private schools were selected. The sample size was allocated as per the number of students in each grade level using the proportional allocation method. Finally systematic random sampling was used to select students. One day before data collection selected adolescent students was provided the consent form with information sheet to be signed by parent/Guardians.

\section{Independent variable/predictors}

Exposure Adverse childhood experiences (ACEs) was assessed using the ACE questionnaire, which addresses 10 item ACEs under three categories: 1. Abuse (emotional, physical and sexual), 2. Neglect (emotional and physical), and 3. Household dysfunction (parental separation/divorce, violence against mother, household substance abuse, household mental illness, and incarceration of the household member). The ACE questionnaire is a reliable, and valid measure of childhood adversity that has been used extensively in large-scale ACE studies [28]. All questions about ACEs pertained to the respondents' first 18 years of life and were binary (yes vs. No). From these, variables were created to reflect any exposure to each ACE subtype (abuse, neglect, household dysfunction). We also calculated a total ACE score for each participant $(+1$ for each of the 10 types of ACE reported). Furthermore, ACE score was treated as a categorical variable $(0,1-3$ or $>3)$ to capture any potential graded relationship with alcohol and chat use. This method of ACE score categorization has been used previously [29].

\section{Dependent variable/outcomes}

The use of alcohol, tobacco, and cigarette smoking was assessed by the following questions: "How many days did you smoke in the last 30 days?" and "How many days did you drink alcohol in the last 30 days?" If the adolescents had chew, smoked, or had drunk alcohol at least once, within the prior 30 days, they were considered as users of cigarettes, tobacco, or alcohol, respectively. This assessment was used by previous studies [30].

\section{Covariates}

In addition to socio-demographic variables, each student also reported the Oslo 3-items social support scale was used to assess social support. A sum index was made by summarizing the raw scores, the sum ranging from $3-14$ [31]. current depression symptoms were assessed by PHQ9 a screening and diagnostic tool with cut point 5 or more symptoms out of 9 items [32]. The questionnaires were prepared in English then translated into Afaan Oromo and Amharic languages for better understanding. Ten second- year MSC psychiatry students were assigned to supervise and disseminate the questionnaires. Before the data collection, one-day training had been given for the supervisors. The supervisors for completeness and consistency of responses had checked the filled questionnaires daily. Before the actual data collection pre-test was made on $5 \%$ of the sample size in Agaro secondary school which is found in other zones near to the study site and necessary correction was taken after the pretest done on the questionnaires.

\section{Data processing and analysis}

Data were entered into Epi data 3.1 and exported to SPSS version 23.0. Chi-square tests were performed to examine any differences in ACE prevalence (cumulative and individual ACEs) by gender and by the current substance use of alcohol and chat, and Logistic regression was used to compute adjusted odds ratios (ORs) and 95\% confidence intervals to assess the association between ACEs and alcohol and chat use among adolescents. An analysis of variance was calculated using the ACE Score as a predictor, and alcohol and chat use as the dependent measure.

\section{Result}

\section{Description of socio-demographics}

Among the total number of 583 distributed questionnaires, 546 were filled completely and consistently making a response rate of $94.3 \%$. The remaining 37 questionnaires were not included in the study as a result of non-response rates collected from all the sampled schools. Of these, $442(81 \%)$ were studying in public schools and $104(19 \%)$ in private schools. Adolescent females outnumbered males. The majority of the participants were from urban area. Their ages ranged from 14 to 19 years with a mean age of 16.83 years (SD \pm 1.26$)$. The majority of respondents $211(38.6 \%)$ were under age 16, 153(28\%) were age 17 and 182(33.3) were above age 18. The majorities (44\%) were Muslims and about (38.8\%) were Christians. Occupation of respondents' father was classified into four categories where $40(7.3 \%)$ were laborers, 219(40.1\%) were merchants, 163 (29.9\%) were government employees, and $124(22.7 \%)$ private employees. Likewise, respondents' mother occupation was under the same category with an additional category namely being a housewife, which accounted for $135(24.7 \%)$ mothers out of the total number of mothers. Five classifications were used to categorize respondents' father and mother educational levels. Accordingly, $150(27.5 \%)$ of the response for fathers' educational level were under the certificate and above category while the number of mothers' educational level for the same category was 102(18.7\%) (Table 1).

\section{Description of substance use among adolescents}

This study shows that a significant number of students use chat chewing behavior (26.6\%) followed by alcohol use (20\%), and a small number of students use cigarette smoking 
and other illicit drug users (0.9\%) (Ganja and Shisha) each (Table 1).

\section{Adverse childhood experience among adolescents}

Table 2 shows among the 546 adolescents who participated in this study, 285(50.7\%) of the participants answered yes to at least one or more questions among the total 10 questions of ACEs. According to the three categories of adverse childhood experience (ACE) from 332 female adolescents, 60(18.1\%) had been abused either physically or sexually, 58(17.6\%) had been neglected and 100(30.4\%) had been household dysfunction. And also from 214 male adolescents 75(34.6\%)

Table 1: Socio demographic profile of adolescents who participated in the study.

\begin{tabular}{|c|c|c|c|}
\hline Variables & Category & Frequency & Percent (\%) \\
\hline \multirow{6}{*}{ age } & 14 & 13 & 2.4 \\
\hline & 15 & 84 & 15.4 \\
\hline & 16 & 114 & 20.9 \\
\hline & 17 & 153 & 28.0 \\
\hline & 18 & 137 & 25.1 \\
\hline & 19 & 45 & 8.2 \\
\hline \multirow{2}{*}{ Sex } & female & 329 & 60.3 \\
\hline & male & 217 & 39.7 \\
\hline \multirow{4}{*}{ Grade } & 9 & 174 & 31.9 \\
\hline & 10 & 153 & 28.0 \\
\hline & 11 & 103 & 18.9 \\
\hline & 12 & 116 & 21.2 \\
\hline \multirow{4}{*}{ Religion } & $\begin{array}{l}\text { Orthodox } \\
\text { Christian }\end{array}$ & 212 & 38.8 \\
\hline & Muslim & 240 & 44.0 \\
\hline & Protestant & 75 & 13.7 \\
\hline & Others & 19 & 3.5 \\
\hline \multirow{2}{*}{ School } & governmental & 442 & 81.0 \\
\hline & Private & 104 & 19.0 \\
\hline \multirow{4}{*}{ Occupation of father } & Laborer & 40 & 7.3 \\
\hline & Merchant & 219 & 40.1 \\
\hline & Private & 124 & 22.7 \\
\hline & governmental & 163 & 29.9 \\
\hline \multirow{5}{*}{ Occupation of mother } & Laborer & 34 & 6.2 \\
\hline & Merchant & 93 & 17.0 \\
\hline & Private & 137 & 25.1 \\
\hline & government & 147 & 26.9 \\
\hline & House wife & 135 & 24.7 \\
\hline \multirow{5}{*}{$\begin{array}{l}\text { Educational status of } \\
\text { father }\end{array}$} & Illiterate & 40 & 7.3 \\
\hline & $1-4$ & 69 & 12.6 \\
\hline & $5-8$ & 124 & 22.7 \\
\hline & $9-12$ & 163 & 29.9 \\
\hline & $\begin{array}{c}\text { certificate and } \\
\text { above }\end{array}$ & 150 & 27.5 \\
\hline \multirow{5}{*}{$\begin{array}{l}\text { Educational status of } \\
\text { mother }\end{array}$} & Illiterate & 51 & 9.3 \\
\hline & $1-4$ & 96 & 17.6 \\
\hline & $5-8$ & 159 & 29.1 \\
\hline & $9-12$ & 138 & 25.3 \\
\hline & $\begin{array}{l}\text { certificate and } \\
\text { above }\end{array}$ & 102 & 18.7 \\
\hline \multirow{2}{*}{ Adolescents residence } & Urban & 450 & 82.4 \\
\hline & Rural & 96 & 17.6 \\
\hline \multirow{4}{*}{$\begin{array}{l}\text { Substance use among } \\
\text { adolescents }\end{array}$} & $\begin{array}{l}\text { Cigarette } \\
\text { smokers }\end{array}$ & 5 & .9 \\
\hline & Alcohol drinkers & 109 & 20 \\
\hline & Chat chewers & 145 & 26.6 \\
\hline & $\begin{array}{c}\text { Other illegal } \\
\text { drugs }\end{array}$ & 5 & .9 \\
\hline
\end{tabular}

Note: Others illegal drugs: - include Ganja, Shisha and Other substances or medication use

\begin{tabular}{|c|c|c|c|c|c|}
\hline \multicolumn{2}{|c|}{$\begin{array}{c}\text { ACEs } \\
\text { Characteristics }\end{array}$} & \begin{tabular}{|c|} 
Boys \\
$(\mathrm{N}=214) \%$
\end{tabular} & $\begin{array}{c}\text { Girls } \\
(\mathrm{N}=332) \%\end{array}$ & $\begin{array}{c}\text { Overall } \\
(\mathrm{N}=546) \%\end{array}$ & $p$ - value \\
\hline \multicolumn{2}{|c|}{ Emotional abuse } & 42.3 & 57.7 & 20.3 & 0.256 \\
\hline \multicolumn{2}{|c|}{ Physical abuse } & 40.7 & 59.3 & 15.8 & 0.422 \\
\hline \multicolumn{2}{|c|}{ Physical neglect } & 39.2 & 60.8 & 9.0 & 0.095 \\
\hline \multicolumn{2}{|c|}{ Emotional neglect } & 38.6 & 61.4 & 12.8 & 0.510 \\
\hline \multicolumn{2}{|c|}{ Sexual Abuse } & 24.2 & 75.8 & 6.0 & 0.049 \\
\hline \multicolumn{2}{|c|}{$\begin{array}{l}\text { Household members substance } \\
\text { abuse }\end{array}$} & 51.9 & 48.1 & 9.5 & 0.035 \\
\hline \multicolumn{2}{|c|}{ Household members incarceration } & 35.5 & 64.5 & 13.9 & 0.283 \\
\hline \multicolumn{2}{|c|}{$\begin{array}{l}\text { Household members mental } \\
\text { illness }\end{array}$} & 40.7 & 59.3 & 4.9 & 0.508 \\
\hline \multicolumn{2}{|c|}{ Family violence } & 39.2 & 60.8 & 5.7 & 0.443 \\
\hline \multicolumn{2}{|c|}{ Parental divorce } & 31.4 & 68.6 & 15.8 & 0.068 \\
\hline \multirow{3}{*}{$\begin{array}{c}\text { For each ACE type } \\
\text { category }\end{array}$} & abuse & 47.9 & 52.1 & 17.6 & 0.036 \\
\hline & neglect & 41.6 & 58.4 & 16.3 & 0.349 \\
\hline & $\begin{array}{l}\text { Household } \\
\text { dysfunction }\end{array}$ & 45.0 & 55.0 & 18.3 & 0.115 \\
\hline \multirow{3}{*}{ ACEs score count } & $\mathrm{ACE}=0$ & 47.7 & 47.9 & 49.3 & 0.012 \\
\hline & ACE 1-3 & 42.1 & 43.4 & 41.0 & 0.000 \\
\hline & $A C E>3$ & 10.3 & 8.7 & 9.7 & 0.050 \\
\hline
\end{tabular}

had abused either physically or sexually, 43(19.6\%) had been neglected and 73(33.6\%) had been household dysfunction (Table 2).

\section{Description of social support}

Measurement by the Oslo Three Items Social Support Scale revealed that $173(31.7 \%)$ of respondents received poor social support, 211(38.6\%) of them had moderate social support while 162(29.7\%) were had strong social support.

\section{Multivariate relationships between ACEs and alcohol and chat consumption risk behaviors}

Regression models were estimated by entering the class variable and covariates simultaneously for each outcome variable, alcohol, and chat use. Each ACE class is compared to the reference group of Low ACEs (ACEs=0). Compared to ACEs=0, High/Multiple ACEs (ACEs=1-3 and above 3) were significantly associated with increased alcohol use behaviors $(\mathrm{AOR}=1.491(1.072-3.078)$ and $\quad(\mathrm{AOR}=3.171(1.330-7.560)$ respectively controlling other risk factors. similarly for chat use High/Multiple ACEs (ACEs=1-3 and above 3) were significantly associated with increased the chat use behaviors by 4.92 times (AOR=4.92, 95\%CI=2.640-8.432) and 11.022 times (AOR=11.022, 95\%CI=1.230-25.560) respectively.

Also, we separately conducted a series of regression analyses to compare adolescents students in three types of ACEs (i.e., Abuse, Neglect, and Household Dysfunction (Tables 3 and 4$)$.

First, we found a significant association with Neglect and Household Dysfunction which increases alcohol use by 1.137 times (AOR=1.137, 95\%CI=1.094-3.175) and 3.028 times (AOR=3.028, 95\%CI=1.548-6.926) respectively. But in chat use behaviors we found a significant association only with household dysfunction increasing it by 2.093 times (AOR=2.093, 95\%CI=1.629-4.897). 
Table 3: Binary and multivariate logistic regression examining the association between predictors and chat use.

\begin{tabular}{|c|c|c|c|c|c|}
\hline \multirow{2}{*}{$\begin{array}{l}\text { Explanatory } \\
\text { variables }\end{array}$} & \multirow{2}{*}{\multicolumn{2}{|c|}{$\begin{array}{l}\text { Variables } \\
\text { category }\end{array}$}} & \multicolumn{3}{|c|}{ Bivariate and Multivariate Analysis } \\
\hline & & & COR & AOR & $p$ - value \\
\hline \multirow[b]{2}{*}{ sex } & \multicolumn{2}{|l|}{ female } & 1 & 1 & \multirow[b]{2}{*}{0.001} \\
\hline & \multicolumn{2}{|l|}{ male } & $\begin{array}{c}1.689 \\
(1.128-3.791)\end{array}$ & $\begin{array}{c}1.312 \\
(1.107-5.219)\end{array}$ & \\
\hline \multirow[b]{2}{*}{ Residence } & \multicolumn{2}{|l|}{ Urban } & 1 & 1 & \\
\hline & \multicolumn{2}{|l|}{ Rural } & $\begin{array}{c}1.260 \\
(1.277-3.062)\end{array}$ & $\begin{array}{c}2.127 \\
(1.213-7.361)\end{array}$ & 0.011 \\
\hline \multirow{3}{*}{$\begin{array}{l}\text { Social support } \\
\text { (Oslo 3) }\end{array}$} & \multicolumn{2}{|l|}{ Poor } & 1 & 1 & \\
\hline & \multicolumn{2}{|l|}{ Moderate } & $\begin{array}{c}1.690 \\
(1.032-2.775)\end{array}$ & $\begin{array}{c}0.748 \\
(0.481-0.950)\end{array}$ & 0.030 \\
\hline & \multicolumn{2}{|l|}{ Strong } & $\begin{array}{c}1.045 \\
(0.673-1.622)\end{array}$ & $\begin{array}{c}0.625 \\
(0.426-0.892)\end{array}$ & 0.001 \\
\hline \multirow{6}{*}{ ACEs type } & \multirow[b]{2}{*}{ Abuse } & No & 1 & & \multirow[b]{2}{*}{0.876} \\
\hline & & Yes & $\begin{array}{c}0.498 \\
(0.308-1.806)\end{array}$ & $\begin{array}{c}0.958 \\
(0.56-1.637)\end{array}$ & \\
\hline & \multirow[b]{2}{*}{ Neglect } & No & 1 & & \multirow[b]{2}{*}{0.935} \\
\hline & & Yes & $\begin{array}{c}0.365 \\
(0.224-0.595)\end{array}$ & $\begin{array}{c}0.966 \\
(0.548-1.701)\end{array}$ & \\
\hline & \multirow[b]{2}{*}{$\begin{array}{l}\text { Household } \\
\text { dysfunction }\end{array}$} & No & 1 & & \multirow[b]{2}{*}{0.001} \\
\hline & & Yes & $\begin{array}{c}3.362 \\
(1.226-5.577)\end{array}$ & $\begin{array}{c}2.093 \\
(1.629-4.897)\end{array}$ & \\
\hline \multirow{3}{*}{$\begin{array}{c}\text { ACE scores } \\
\text { category }\end{array}$} & \multicolumn{2}{|l|}{$\mathrm{ACE}=0$} & 1 & 1 & \\
\hline & \multicolumn{2}{|l|}{$A C E=1-3$} & $\begin{array}{c}3.920 \\
(3.046-10.185)\end{array}$ & $\begin{array}{c}4.92 \\
(2.640-8.432)\end{array}$ & 0.040 \\
\hline & \multicolumn{2}{|l|}{$A C E>3$} & $\begin{array}{c}5.449 \\
(2.435-8.445)\end{array}$ & $\begin{array}{c}11.022 \\
(1.230-25.560)\end{array}$ & 0.001 \\
\hline
\end{tabular}

$\mathrm{N}: \mathrm{B}$ In this model $\mathrm{R}^{2}=0.32, \mathrm{~F}(1,544)=82.609, p<0.001$

Table 4: Binary multivariate logistic regression examining the association between predictors and alcohol use.

\begin{tabular}{|c|c|c|c|c|c|}
\hline \multirow{2}{*}{$\begin{array}{l}\text { Explanatory } \\
\text { variables }\end{array}$} & \multirow{2}{*}{\multicolumn{2}{|c|}{$\begin{array}{l}\text { Variables } \\
\text { category }\end{array}$}} & \multicolumn{3}{|c|}{ Bivariate and Multivariate Analysis } \\
\hline & & & COR & AOR & $p$ - value \\
\hline \multirow[b]{2}{*}{ sex } & \multicolumn{2}{|l|}{ female } & 1 & 1 & \\
\hline & \multicolumn{2}{|l|}{ male } & $\begin{array}{c}2.473 \\
(1.614-3.791)\end{array}$ & $\begin{array}{c}2.603 \\
(1.657-4.089)\end{array}$ & 0.001 \\
\hline \multirow{5}{*}{$\begin{array}{c}\text { Educational status } \\
\text { of father }\end{array}$} & \multicolumn{2}{|l|}{ Illiterate } & 1 & 1 & \\
\hline & \multicolumn{2}{|l|}{$1-4$} & $\begin{array}{c}7.30 \\
(2.40-9.753)\end{array}$ & $\begin{array}{c}7.247 \\
(1.604-32.691)\end{array}$ & .010 \\
\hline & \multicolumn{2}{|l|}{$5-8$} & $\begin{array}{c}0.744 \\
(0.358-1.547)\end{array}$ & $\begin{array}{c}1.752 \\
(0.804-3.820)\end{array}$ & .158 \\
\hline & \multicolumn{2}{|l|}{$9-12$} & $\begin{array}{c}0.881 \\
(0.496-1.565)\end{array}$ & $\begin{array}{c}1.457 \\
(0.788-2.613)\end{array}$ & .230 \\
\hline & \multicolumn{2}{|c|}{ Certificate and above } & $\begin{array}{c}0.834 \\
(0.489-1.422)\end{array}$ & $\begin{array}{c}1.329 \\
(0.754-2.343)\end{array}$ & .325 \\
\hline \multirow{3}{*}{$\begin{array}{l}\text { Social support } \\
\text { (Oslo 3) }\end{array}$} & \multicolumn{2}{|l|}{ Poor } & 1 & 1 & \\
\hline & \multicolumn{2}{|l|}{ Moderate } & $\begin{array}{c}0.537 \\
(0.314-0.916)\end{array}$ & $\begin{array}{c}0.649 \\
(0.364-0.956)\end{array}$ & 0.02 \\
\hline & \multicolumn{2}{|l|}{ Strong } & $\begin{array}{c}0.528 \\
(0.309-0.900)\end{array}$ & $\begin{array}{c}0.219 \\
(0.117-0.708)\end{array}$ & 0.001 \\
\hline \multirow{6}{*}{ ACEs type } & \multirow[b]{2}{*}{ Abuse } & No & 1 & & \\
\hline & & Yes & $\begin{array}{c}0.65 \\
(0.390-1.090)\end{array}$ & $\begin{array}{c}0.901 \\
(0.489-1.659)\end{array}$ & 0.213 \\
\hline & \multirow[b]{2}{*}{ Neglect } & No & 1 & & \multirow[b]{2}{*}{0.013} \\
\hline & & Yes & $\begin{array}{c}0.538 \\
(0.321-0.900)\end{array}$ & $\begin{array}{c}1.137 \\
(1.094-3.175)\end{array}$ & \\
\hline & \multirow[b]{2}{*}{$\begin{array}{l}\text { Household } \\
\text { dysfunction }\end{array}$} & No & 1 & & \multirow[b]{2}{*}{0.001} \\
\hline & & Yes & $\begin{array}{c}0.609 \\
(0.369-1.007)\end{array}$ & $\begin{array}{c}3.028 \\
(1.548-6.926)\end{array}$ & \\
\hline \multirow{3}{*}{$\begin{array}{l}\text { ACE scores } \\
\text { category }\end{array}$} & \multicolumn{2}{|l|}{$\mathrm{ACE}=0$} & 1 & 1 & \\
\hline & \multicolumn{2}{|l|}{$A C E=1-3$} & $\begin{array}{c}1.247 \\
(1.028-3.477)\end{array}$ & $\begin{array}{c}1.491 \\
(1.072-3.078)\end{array}$ & 0.009 \\
\hline & \multicolumn{2}{|l|}{$A C E>3$} & $\begin{array}{c}4.524 \\
(2.278-6.988)\end{array}$ & $\begin{array}{c}3.171 \\
(1.330-7.560)\end{array}$ & 0.021 \\
\hline \multirow[t]{2}{*}{ Current depression } & \multicolumn{2}{|l|}{ Yes } & $\begin{array}{c}4.036 \\
(2.090-7.793)\end{array}$ & $\begin{array}{c}2.128 \\
(1.055-8.291)\end{array}$ & \\
\hline & \multicolumn{2}{|l|}{ No } & 1 & 1 & \\
\hline
\end{tabular}

$\mathrm{N}: \mathrm{B}$ In this Model $\mathrm{R}^{2}=0.250, \mathrm{~F}(9,536)=19.836, p<0.001$
In examining the association between ACEs and alcohol, and chat use, male sex was a significant predictor. With being male increase alcohol and chat use by 2.603 times (AOR=2.603, $95 \% \mathrm{CI}=1.657-4.089)$ and 1.312 times (AOR=1.312, $95 \% \mathrm{CI}=1.107-5.219$ ) respectively.

In the model predicting alcohol use, father's educational status and current depression level were both significant predictors, that having grade 1-4 increases alcohol use by 7.247 times (AOR=7.247, 95\% CI=1.604-32.691) as compared with illiterate. And the current depression level increases alcohol use by 2.128 times (AOR=2.128, 95\%CI=1.055-8.291) as compared to non-depressed.

In a final model predicting chat use behaviors, the residence was a significant predictor, that coming from the rural area of Jimma zone increases chat use by 2.127 times (AOR=2.127, $95 \% \mathrm{CI}=1.213-7.361$ ) as compared urban.

In a final model predicting alcohol and chat use behaviors, social supports were a significant predictor. Taking poor social support as reference, having moderate and strong social support decreases alcohol use by $35.1 \%(\mathrm{AOR}=0.649$, $95 \% \mathrm{CI}=0.364-0.956)$ and $78.1 \%(\mathrm{AOR}=0.219,95 \% \mathrm{CI}=0.117$ $0.708)$ respectively and by $25.2 \%(\mathrm{AOR}=0.748,95 \% \mathrm{CI}=0.481$ 0.950 ) and $37.7 \% 9 \mathrm{AOR}=0.625,95 \% \mathrm{CI}=0.426-0.892$ ) decreases chat use respectively (Tables 3 and 4).

\section{Discussion}

The findings of this study revealed that the commonly abused drugs among school-going adolescents were alcohol $20 \%$, and chat $26.6 \%$. This finding alcohol use was slightly lower than the study done in Northwest Ethiopia, Woreta town (59\%) but chat use was higher than these studies, which was (13.8\%) [33]. A Possible reason for the difference might be the cultural difference of study population that alcohol use was common in the north part of Ethiopia (Woreta), and chat use was in the eastern part (Jimma). The Prevalence of chat use was an almost similar study done in the eastern part of Ethiopia (Harare town) which was $24.2 \%$ (95\%CI 22.2\% 26.2\%) [34].

Most high school adolescents drink and chew because they want to experiment with alcohol, and chat, some drink and chew for the thrill of it, and others because it helps them relax. A new study finds that the fourth group of high school students share all those reasons for drinking, but they also drink and chew to get away from problems and to deal with anger or frustration issues and one of these problems is ACEs $[35,36]$.

In the regression model alcohol use, the association between adverse childhood experiences and alcohol use behaviors were significant when other covariates were adjusted. Table 3 also shows that Graded associations of cumulated adverse childhood experiences with the outcome variables were 
evident that the risk increases with ACEs count $13 \%, 24.1 \%$ and $37.7 \%$ for ACEs=0, ACEs=1-3, and ACEs. $>3$ respectively. And also from the subtype, we found a significant association with Neglect and Household Dysfunction which increases alcohol use by 1.137 times $(\mathrm{AOR}=1.137,95 \% \mathrm{CI}=1.094$ 3.175 ) and 3.028 times (AOR=3.028, 95\%CI=1.548-6.926) respectively. This finding was similar to other studies done outside Ethiopia [37-40].

These findings provide evidence that emotional, psychological, and physical abuse, neglect, and household dysfunction are stressful, and traumatic factors in the childhood family environment are strongly associated with the initiation of alcohol use, particularly during early to midadolescence. ACEs influence the use of alcohol at an early age despite Ethiopian social and government efforts to delay its use through a variety of public health messages, and laws prohibiting alcohol use before age 21 [27].

And also in the second regression model predicting chat use, we found similar findings as to the first model that the association between adverse childhood experiences and chat use behaviors were significant when other covariates were adjusted. High/Multiple ACEs (ACEs=1-3 and above 3) increased chat use behaviors by 4.92 times $(A O R=4.92$, $95 \% \mathrm{CI}=2.640-8.432)$ and 11.022 times (AOR=11.022, $95 \% \mathrm{CI}=1.230-25.560)$ respectively. And from a subtype of ACEs household dysfunction increasing chat by 2.093 times $(\mathrm{AOR}=2.093,95 \% \mathrm{CI}=1.629-4.897)$. This finding was in line with other previous studies $[41,42]$.

In both regression models, our findings indicate that males have higher odds of drinking and chewing than females (1.312; 95\%CI= (1.107-5.219) and 2.603; 95\%=1.657-4.089) for alcohol and chat predicting models respectively. This is a common finding in alcohol and chat use studies where males use substances more and show a higher tendency for dependence than females $[43,44]$.

And also social support was the only significant factor to decrease the risk of alcohol and chat use. Having moderate and strong social support compared with poor social support decreases alcohol use by $35.1 \%$ and $78.1 \%$ respectively. And by $23.2 \%$ and $37.5 \%$ decreases chat use when moderate and strong social support compared to poor social support respectively. This finding was in line with many other studies $[45,46]$. Social supports as mediators were related to decreasing the effect of negative life events, specifically ACEs and deviant peer affiliations [47].

Furthermore in the alcohol regression model, the current level of depression and father educational level was found to be significant. Having grade level (1-4) increases alcohol use by 7.247 times (AOR=7.247, 95\%CI=1.604-32.691) as compared with illiterate. In line with other study being educated decreases alcohol use that they will have good awareness than not educated $[48,49]$.
And the current depression level increases alcohol use by 2.128 times $(\mathrm{AOR}=2.128,95 \% \mathrm{CI}=1.055-8.291)$ as compared to non-depressed. As money, other studies revealed depression can be the risk and outcome of alcohol use [50].

Finally, in the chat use regression model, residence found a significant predictor of chat use. That coming from the rural area of Jimma zone increases chat use by 2.127 times $(A O R=2.127,95 \% \mathrm{CI}=1.213-7.361)$ as compared urban. In line with study done in Ethiopia access and tradition of rural area is more risk for chat use than the urban area [50].

But studies done in Bahr Dar and Saudi Arabia reported that chat chewing were more prevalent in urban participants than rural participants [51,52]. This may be due to study population difference; the more liberal lifestyles in urban areas compared to cultural conservatism in rural areas and may also be attributed to the easiness of reporting chewing khat by urban adolescents than the rural residents [52].

To our knowledge, this is one of the very few studies to see the association of ACEs and substance use (alcohol and chat) use among adolescent students. We used appropriate sampling procedure and analysis methods utilized were appropriate to the study and considered as the strength of the study. The study provides useful information that will inform policymakers to design a strategy to reduce the prevalence of ACEs and substance use (alcohol drinking and chat chewing) habit and its adverse social and health consequences.

This study was based on a cross-sectional survey; causality cannot be inferred from our findings. Based on self-response for sensitive issues can invite social desirability bias and therefore underestimate utilization of alcohol drinking and chat chewing. The study was on school-going adolescents; therefore impedes generalization to all adolescents in Ethiopia indicating a need for further study using a more representative sample of adolescents in the country.

\section{Conclusion and recommendation}

In conclusion, our findings indicate that there are high levels of alcohol drinking and chat chewing among the sampled school-going adolescent students. ACEs are strongly associated with early initiation of alcohol and chat use among school-going adolescents. Practical steps with families and guardians seek to reduce ACEs. Parents, as well as school and health authorities, need to work more toward awareness creation about the hazards of alcohol drinking and chat chewing and the importance of social support to decrease the effects of past ACEs.

\section{Declaration}

\section{Ethics approval and consent to participate}

We obtained ethical approval from the Ethical Review Committee of the College of Health Sciences, Jimma 
University. We obtained further permission to conduct the research from the respective Jimma zone educational office. Written informed consent and ascent was obtained from each participant. We kept privacy and confidentiality by replacing all names with codes and by keeping all the data we collected in a locked bag.

\section{Funding}

This research was supported by Wollo University. The funder has no role in the interpretation of findings and decision for publication.

\section{Authors contributions}

MT conceived and designed the study. MT, MN, AB, and WM analyzed the data and drafted the manuscript. All the authors read the manuscript several times and have given their final approval for publication.

\section{Acknowledgement}

We would like to thank Jimma zone school administrators and students who gave us support and information. We also would like to thank MSC students of ICCMH for their genuine help, especially during the data collection and data entry of this study.

\section{References}

1. Denton DA. National Health and Medical Research Council (NHMRC) 2009. 2009.

2. Moore E, Coffey C, Carlin JB, Alati R, Patton GC. Assessing alcohol guidelines in teenagers: results from a 10 year prospective study. Aus New Zealand J Public Health. 2009; 33: 154-159.

3. Degenhardt L, Stockings E, Patton G, Hall WD, Lynskey M. The increasing global health priority of substance use in young people. The Lancet Psychiatry. 2016; 3: 251-264.

PubMed: https://pubmed.ncbi.nlm.nih.gov/26905480/

4. Simons-Morton B, Haynie D, Liu D, Chaurasia A, Li K, et al. The effect of residence, school status, work status, and social influence on the prevalence of alcohol use among emerging adults. J Studies Alcohol Drugs. 2016; 77: 121-132.

PubMed: https://pubmed.ncbi.nlm.nih.gov/26751362/

5. Kuntsche E, Rossow I, Simons Morton B, Bogt TT, Kokkevi A, Godeau E. Not Early Drinking but Early Drunkenness Is a Risk Factor for Problem Behaviors Among Adolescents from $38 \mathrm{E}$ uropean and $\mathrm{N}$ orth A merican Countries. Alcohol Clin Exp Res. 2013;37: 308-314.

PubMed: https://pubmed.ncbi.nlm.nih.gov/23240610/

6. Degenhardt L, Glantz M, Evans Lacko S, Sadikova E, Sampson N et al. Estimating treatment coverage for people with substance use disorders: an analysis of data from the World Mental Health Surveys. World Psychiatry. 2017; 16: 299-307.

PubMed: https://pubmed.ncbi.nlm.nih.gov/28941090/

7. Organization WH. Global status report on alcohol and health 2018: World Health Organization; 2019.

8. Monti PM, Miranda Jr R, Nixon K, Sher KJ, Swartzwelder HS, et al. Adolescence: booze, brains, and behavior. Alcoholism: Clinical and Experimental Research. 2005; 29: 207-220.

PubMed: https://pubmed.ncbi.nlm.nih.gov/15714044/

9. Witt ED. Research on alcohol and adolescent brain development: opportunities and future directions. Alcohol. 2010; 44: 119-124. PubMed: https://pubmed.ncbi.nlm.nih.gov/20113880/
10. Olawole-Isaac A, Ogundipe O, Amoo EO, Adeloye D. Substance use among adolescents in sub-Saharan Africa: A systematic review and meta-analysis. South African J Child Health. 2018;12: s79-s84.

\section{1.. !!! INVALID CITATION !!!}

12. Hughes K, Bellis MA, Hardcastle KA, Sethi D, Butchart A, Mikton C, et al. The effect of multiple adverse childhood experiences on health: a systematic review and meta-analysis. The Lancet Public Health. 2017; 2: e356-e366.

PubMed: https://pubmed.ncbi.nlm.nih.gov/29253477/

13.Pereda N, Guilera G, Forns M, Gómez-Benito J. The prevalence of child sexual abuse in community and student samples: A meta-analysis. Clin Psychol Rev. 2009; 29: 328-338.

PubMed: https://pubmed.ncbi.nlm.nih.gov/19371992/

14.Stoltenborgh M, Bakermans-Kranenburg MJ, Alink LR, Van ljzendoorn $\mathrm{MH}$. The universality of childhood emotional abuse: a meta-analysis of worldwide prevalence. J Aggression, Maltreatment \& Trauma. 2012; 21: 870-890.

15. Jansen HA, Watts C, Ellsberg M, Heise L, Garcia-Moreno C. Interviewer training in the WHO multi-country study on women's health and domestic violence. Violence Against Women. 2004; 10: 831-849.

16.Bartley M. Life gets under your skin: UCL, Research Departement of Epidemiology and Public Health; 2012.

17.Anda R. The health and social impact of growing up with adverse childhood experiences: The human and economic costs of the status quo. Centers for Disease Control and Prevention. 2007.

18.Campbell JA, Walker RJ, Egede LE. Associations between adverse childhood experiences, high-risk behaviors, and morbidity in adulthood. Am J Prev Med. 2016; 50: 344-352.

PubMed: https://pubmed.ncbi.nlm.nih.gov/26474668/

19. Hillis SD, Anda RF, Felitti VJ, Marchbanks PA. Adverse childhood experiences and sexual risk behaviors in women: a retrospective cohort study. Family planning perspectives. 2001: 206-211.

PubMed: https://pubmed.ncbi.nlm.nih.gov/11589541/

20.Bellis MA, Lowey H, Leckenby N, Hughes K, Harrison D. Adverse childhood experiences: retrospective study to determine their impact on adult health behaviours and health outcomes in a UK population. $J$ Public Health. 2014; 36: 81-91.

PubMed: https://pubmed.ncbi.nlm.nih.gov/23587573/

21.Forster M, Grigsby TJ, Rogers CJ, Benjamin SM. The relationship between family-based adverse childhood experiences and substance use behaviors among a diverse sample of college students. Addict Behav. 2018; 76: 298-304.

PubMed: https://pubmed.ncbi.nlm.nih.gov/28889058/

22.Allem J-P, Soto DW, Baezconde-Garbanati L, Unger JB. Adverse childhood experiences and substance use among Hispanic emerging adults in Southern California. Addict Behav. 2015; 50: 199-204. PubMed: https://pubmed.ncbi.nlm.nih.gov/26160522/

23.Lee K, Pang YC, Lee JAL, Melby JN. A study of adverse childhood experiences, coping strategies, work stress, and self-care in the child welfare profession. Human Service Organizations: Management, Leadership \& Governance. 2017; 41: 389-402.

24.Richard A, Rohrmann S, Vandeleur CL, Schmid M, Barth J, et al Loneliness is adversely associated with physical and mental health and lifestyle factors: Results froma Swiss national survey. PLoS One. 2017;12. PubMed: https://pubmed.ncbi.nlm.nih.gov/28715478/

25.Armstrong MI, Birnie-Lefcovitch S, Ungar MT. Pathways between social support, family well being, quality of parenting, and child resilience: What we know. J Child Family Studies. 2005; 14: 269-281.

26. Blum RW, Li M, Naranjo-Rivera G. Measuring adverse child experiences among young adolescents globally: Relationships with depressive symptoms and violence perpetration. J Adolescent Health. 2019; 65: 86-93.

PubMed: https://pubmed.ncbi.nlm.nih.gov/30930089/ 
27.Reda AA, Moges A, Wondmagegn BY, Biadgilign S. Alcohol drinking patterns among high school students in Ethiopia: a cross-sectional study. BMC Public Health. 2012; 12: 213.

PubMed: https://pubmed.ncbi.nlm.nih.gov/22433230/

28. Ho GW, Chan AC, Chien WT, Bressington DT, Karatzias T. Examining patterns of adversity in Chinese young adults using the Adverse Childhood Experiences-International Questionnaire (ACE-IQ). Child Abuse Neglect. 2019; 88: 179-188.

PubMed: https://pubmed.ncbi.nlm.nih.gov/30513406/

29.Anda RF, Croft JB, Felitti VJ, Nordenberg D, Giles WH, et al. Adverse childhood experiences and smoking during adolescence and adulthood. JAMA. 1999; 282: 1652-1658.

PubMed: https://pubmed.ncbi.nlm.nih.gov/10553792/

30.Gonçalves H, Soares ALG, Santos APGd, Ribeiro CG, Bierhals IO, Vieira LS, et al. Adverse childhood experiences and consumption of alcohol, tobacco and illicit drugs among adolescents of a Brazilian birth cohort. Cadernos de saude publica. 2016; 32: e00085815.

PubMed: https://pubmed.ncbi.nlm.nih.gov/27828612/

31.Kocalevent R-D, Berg L, Beutel ME, Hinz A, Zenger M, Härter M, et al. Social support in the general population: standardization of the Oslo social support scale (OSSS-3). BMC Psychol. 2018; 6: 31.

PubMed: https://pubmed.ncbi.nlm.nih.gov/30016997/

32. Gelaye B, Williams MA, Lemma S, Deyessa N, Bahretibeb Y, Shibre T, et al. Validity of the patient health questionnaire-9 for depression screening and diagnosis in East Africa. Psychiatry Res. 2013; 210: 653-661. PubMed: https://pubmed.ncbi.nlm.nih.gov/23972787/

33. Birhanu AM, Bisetegn TA, Woldeyohannes SM. High prevalence of substance use and associated factors among high school adolescents in Woreta Town, Northwest Ethiopia: multi-domain factor analysis. BMC public health. 2014; 14: 1186.

PubMed: https://pubmed.ncbi.nlm.nih.gov/25410657/

34.Reda AA, Moges A, Biadgilign S, Wondmagegn BY. Prevalence and determinants of khat (Catha edulis) chewing among high school students in eastern Ethiopia: a cross-sectional study. PLoS One. 2012; 7. PubMed: https://pubmed.ncbi.nlm.nih.gov/22479484/

35. Copeland LA, Shope JT, Waller PF. Factors in adolescent drinking/ driving: binge drinking, cigarette smoking, and gender. J School Health. 1996; 66: 254-260.

PubMed: https://pubmed.ncbi.nlm.nih.gov/8884665/

36. Ellickson PL, McGUIGAN KA, Adams V, Bell RM, Hays RD. Teenagers and alcohol misuse in the United States: by any definition, it's a big problem. Addiction. 1996; 91: 1489-1503.

37.Kim YH. Associations of adverse childhood experiences with depression and alcohol abuse among Korean college students. Child abuse \& neglect. 2017; 67: 338-348.

PubMed: https://pubmed.ncbi.nlm.nih.gov/28351730/

38. Duke NN, Pettingell SL, McMorris BJ, Borowsky IW. Adolescent violence perpetration: associations with multiple types of adverse childhood experiences. Pediatrics. 2010; 125: e778-e86.

PubMed: https://pubmed.ncbi.nlm.nih.gov/20231180/

39.Dube SR, Miller JW, Brown DW, Giles WH, Felitti VJ, Dong M, et al. Adverse childhood experiences and the association with ever using alcohol and initiating alcohol use during adolescence. J Adolescent
Health. 2006; 38: 444. e1-e10.

PubMed: https://pubmed.ncbi.nlm.nih.gov/16549308/

40.Dube SR, Anda RF, Felitti VJ, Edwards VJ, Croft JB. Adverse childhood experiences and personal alcohol abuse as an adult. Addictive Behaviors. 2002; 27: 713-725.

PubMed: https://pubmed.ncbi.nlm.nih.gov/12201379/

41.Kiburi SK, Molebatsi K, Obondo A, Kuria MW. Adverse childhood experiences among patients with substance use disorders at a referral psychiatric hospital in Kenya. BMC Psychiatry. 2018; 18: 197. PubMed: https://pubmed.ncbi.nlm.nih.gov/29914409/

42.Belew M, Kebede D, Kassaye M, Enquoselassie F. The magnitude of khat use and its association with health, nutrition and socio-economic status. Ethiopian Med J. 2000; 38:11-26.

PubMed: https://pubmed.ncbi.nlm.nih.gov/11144876/

43. Odenwald M, Neuner F, Schauer M, Elbert T, Catani C, Lingenfelder B, et al. Khat use as risk factor for psychotic disorders: a cross-sectional and case-control study in Somalia. BMC Med. 2005; 3: 5. PubMed: https://pubmed.ncbi.nlm.nih.gov/15707502/

44.Aldridge RW, StoryA, Hwang SW, NordentoftM, LuchenskiSA, Hartwell G, et al. Morbidity and mortality in homeless individuals, prisoners, sex workers, and individuals with substance use disorders in high-income countries: a systematic review and meta-analysis. The Lancet. 2018; 391: 241-250.

PubMed: https://pubmed.ncbi.nlm.nih.gov/29137869/

45.Wills TA, Vaughan R. Social support and substance use in early adolescence. J Behav Med. 1989; 12: 321-339. PubMed: https://pubmed.ncbi.nlm.nih.gov/2600962/

46. Wills TA, Cleary SD. How are social support effects mediated? A test with parental support and adolescent substance use. J Personality Soc Psychol. 1996; 71: 937.

PubMed: https://pubmed.ncbi.nlm.nih.gov/8939042/

47.Piko B. Perceived social support from parents and peers: Which is the stronger predictor of adolescent substance use? Substance use \& misuse. 2000; 35: 617-630.

PubMed: https://pubmed.ncbi.nlm.nih.gov/10741544/

48.Chaffin M, Silovsky JF, Funderburk B, Valle LA, Brestan EV, et al Parent-child interaction therapy with physically abusive parents: efficacy for reducing future abuse reports. J Consulting Clin Psychol. 2004; 72: 500-510.

PubMed: https://pubmed.ncbi.nlm.nih.gov/15279533/

49. Reyno SM, McGrath PJ. Predictors of parent training efficacy for child externalizing behavior problems-a meta analytic review. J Child Psychol Psychiatry. 2006; 47: 99-111.

PubMed: https://pubmed.ncbi.nlm.nih.gov/16405646/

50.Conner KR, Pinquart M, Gamble SA. Meta-analysis of depression and substance use among individuals with alcohol use disorders. J Substance Abuse Treatment. 2009; 37: 127-137.

PubMed: https://pubmed.ncbi.nlm.nih.gov/19150207/

51.Mulugeta $\mathrm{Y}$. Khat chewing and its associated factor among college students in Bahir Dar Town, Ethiopia. Science J Public Health. 2013; 1: 209-214.

52.Ageely HM. Prevalence of Khat chewing in college and secondary (high) school students of Jazan region, Saudi Arabia. Harm Reduction J. 2009; 6: 11. 